\title{
CORRECTION
}

\section{Correction to: Healthy knees have a highly variable patellofemoral alignment: a systematic review}

\author{
Bettina Hochreiter ${ }^{1}$. Silvan Hess ${ }^{2,4} \cdot$ Lukas Moser $^{2,3} \cdot$ Michael T. Hirschmann $^{2,3} \cdot$ Felix Amsler $^{5} \cdot$ Henrik Behrend $^{1}$ (1)
}

Published online: 13 September 2019

(c) European Society of Sports Traumatology, Knee Surgery, Arthroscopy (ESSKA) 2019

\section{Correction to: \\ Knee Surgery, Sports Traumatology, Arthroscopy \\ https://doi.org/10.1007/s00167-019-05587-z}

Authors would like to add the below acknowledgement statement to the original article.

Acknowledgements Figure 1 was adapted with permission from Richard Norris, The Knee Resource.

Publisher's Note Springer Nature remains neutral with regard to jurisdictional claims in published maps and institutional affiliations.

The original article can be found online at https://doi.org/10.1007/ s00167-019-05587-z.

Henrik Behrend

henrik.behrend@kssg.ch

1 Department of Orthopaedic Surgery and Traumatology,

Kantonsspital St. Gallen, Rorschacherstrasse 95,

9007 St. Gallen, Switzerland

2 Department of Orthopaedic Surgery and Traumatology, Kantonsspital Baselland (Bruderholz, Liestal, Laufen),

4101 Bruderholz, Switzerland

3 University of Basel, Basel, Switzerland

4 University of Bern, Bern, Switzerland

5 Amsler Consulting, Basel, Switzerland 